\title{
The delaying effect of financing constraints on investment
}

\author{
Citation for published version (APA):
}

van de Laar, M. M., \& Letterie, W. A. (2003). The delaying effect of financing constraints on investment. METEOR, Maastricht University School of Business and Economics. METEOR Research Memorandum No. 001 https://doi.org/10.26481/umamet.2003001

Document status and date:

Published: 01/01/2003

DOI:

10.26481/umamet.2003001

Document Version:

Publisher's PDF, also known as Version of record

\section{Please check the document version of this publication:}

- A submitted manuscript is the version of the article upon submission and before peer-review. There can be important differences between the submitted version and the official published version of record.

People interested in the research are advised to contact the author for the final version of the publication, or visit the DOI to the publisher's website.

- The final author version and the galley proof are versions of the publication after peer review.

- The final published version features the final layout of the paper including the volume, issue and page numbers.

Link to publication

\footnotetext{
General rights rights.

- You may freely distribute the URL identifying the publication in the public portal. please follow below link for the End User Agreement:

www.umlib.nl/taverne-license

Take down policy

If you believe that this document breaches copyright please contact us at:

repository@maastrichtuniversity.nl

providing details and we will investigate your claim.
}

Copyright and moral rights for the publications made accessible in the public portal are retained by the authors and/or other copyright owners and it is a condition of accessing publications that users recognise and abide by the legal requirements associated with these

- Users may download and print one copy of any publication from the public portal for the purpose of private study or research.

- You may not further distribute the material or use it for any profit-making activity or commercial gain

If the publication is distributed under the terms of Article $25 \mathrm{fa}$ of the Dutch Copyright Act, indicated by the "Taverne" license above, 


\title{
"The delaying effect of financing constraints on investment"
}

\author{
Mindel van de Laar $^{\mathrm{a}}$ \\ Wilko Letterie ${ }^{\mathrm{b}}$ \\ November 2002 \\ ${ }^{a}$ Department of Economics, Maastricht University, the Netherlands \\ bepartment of Strategy, BIRC and Center of Strategy Studies, Maastricht University, the \\ Netherlands
}

Address:

Mindel van de Laar

University of Maastricht

Faculty of Economics and Business Administration

Department of Economics

P.O. Box 616

6200 MD Maastricht

the Netherlands

Telephone: $\quad+31(0) 433882685$

Fax: $\quad+31(0) 433884864$

E-mail: $\quad$ m.vandelaar@algec.unimaas.nl

Acknowledgement:

Wilko Letterie acknowledges support by the PIONIER program of the Dutch Foundation for Scientific Research (NWO). Furthermore, we would like to thank Allard Bruinshoofd, Gerard Pfann and Samuel Mongrut Montalvan for useful comments and conversations. 


\title{
"The delaying effect of financing constraints on investment"
}

\begin{abstract}
:
We develop a simple model in which a firm considers a number of investment projects. Because of limited financial resources, the firm can undertake at most one project. In line with the literature on real options we stress features like irreversibility, uncertainty and the possibility to postpone the investment decision and argue that financing constraints tend to increase the value of waiting.
\end{abstract}

JEL codes: D81, D92

Key words: financing constraints, irreversible investment, uncertainty. 


\section{Introduction}

The lack of unlimited financial means influences our decision making significantly, in all levels of society. Often firms or consumers cannot buy everything they would like, due to the presence of financial constraints. Financial constraints may force a consumer to decide whether to buy a new car or to replace the kitchen instead of doing both. But besides choosing between buying the car or the kitchen at this moment the consumer also has the possibility to wait with its investment. It is very well possible that the car brakes down next year and he or she will have to buy a new car then. The presence of uncertainty will lead to an incentive to postpone the investment.

Examples in other fields are also numerous. In this paper we will focus on a firm's investment decision. In our analysis an investment is irreversible. Once the firm has invested in a certain project, it will not be possible to recover the initial expenses and use these to start an alternative project later. Similarly, it will not be able to restart the same project at better terms later. Furthermore, the future value of the various projects is surrounded with uncertainty and there is the possibility for the firm to postpone its investment decision.. The real options approach predicts that the incentive to postpone the investment increases with the amount of uncertainty surrounding the future valuation of the project. Hence the higher the uncertainty the higher the probability the firm will suspend investing. These assumptions are standard in the real options approach advanced by Dixit and Pindyck (1994).

We will make a distinction between a firm that does not face any binding financial constraints and can invest in all projects that are considered profitable, and a firm that can only undertake at most one project due to a binding financial constraint and therefore las to choose how to spend its money best. This last case is in line with the literature that stresses the role of capital market imperfections due to which some firms may face credit rationing 
(Hubbard, 1998). This financial obstacle to investment decisions in combination with assumptions standard in the literature on irreversible investment under uncertainty has received very little attention so far. ${ }^{1}$

The paper proceeds as follows. In section 1 we briefly present the case where a firm decides upon the timing of investing its resources in one project. In section 2 we introduce the presence of a second project and allow for financial constraints. Next we discuss the more general case of $N$ projects in section 3 . Finally section 4 concludes.

\section{One investment project}

In this section we present a stylized model that captures the main elements of the recent literature on investment under uncertainty (see Dixit and Pindyck, 1994). Consider a firm that has an investment opportunity called project A. If the firmdecides to invest in period 1 the net return of the investment is equal to $V_{A}{ }^{1}$. It is useful to note that we do not model the cost of investing explicitly in our model. In fact the net return defined by $V_{i}^{t}$, where $i$ indicates a project and $t$ denotes period $\mathrm{t}$, should be interpreted as the value of the project minus the sunk cost of investing. The net present value rule suggests to invest as soon as $V_{A}{ }^{l}>0$. However, the recent literature on investment argues that the value of $V_{A}{ }^{l}$ should be compared with the expected net present value the investment yields if the firm delays its decision. Suppose that the firm also has the option to start project $\mathrm{A}$ in period 2. Without loosing generality we abstract from discounting. Then if the firm invests in period 2 the net value of the project is equal to $V_{A}^{2}$. If the firm invests in the first period, it is impossible to recover the initial sunk cost of investment and to restart the project in period 2. This precludes the firm

\footnotetext{
1 Scarramozino (1997) deals with irreversible investment and finance constraints in the context of
} 
from setting up the project at better terms in priod 2 and to acquire the potentially larger value $V_{A}^{2}$, because the initial investment is irreversible. To capture the notion that future realizations are uncertain, we presume that $V_{A}^{2}$ is a random variable which is uniformly distributed on the interval [î -ó, ì +ó]. Both ì and ó are strictly positive. The parameter ì denotes the expected value of $V_{A}^{2}$. The variance of $V_{A}^{2}$ equals $o^{2}$. Therefore, a higher ó implies a higher degree of uncertainty surrounding the future benefits of the project. Uncertainty may be due to discretionary tax and subsidy policies regarding investment by the government of the host countries. Macroeconomic conditions like inflation may also be a determinant of uncertainty and unforeseen events in this respect may force the Central Banks to change interest rates affecting the cost of investment and the demand for products.

We assume it is not possible to postpone the investment decision even after period 2. Therefore, if the firm's management has delayed the investment decision in period 1 it will undertake project $\mathrm{A}$ in period 2 if the realization of $V_{A}^{2}$ exceeds zero. In case the firm does not invest in period 2 the investment option is foregone. We assume that ì <ó. This assumption implies that the probability that the firm does not implement project $\mathrm{A}$ in the second period is strictly positive, because in the worst case scenario $V_{A}^{2}=\grave{i}-$ ó $<0$. We believe this feature of the model to be realistic. The case where ì<ó is definitely more interesting than the alternative case, because then the expected value of the project in period 2 is always positive and equal to ì. As a consequence comparing the returns of period 1 and period two, $V_{A}{ }^{l}$ and ì respectively, does not allow a role for uncertainty. Therefore, we only consider the case where ì <ó. To decide whether the firm should invest in period 1 it calculates the expected value of the option to invest in the second period:

$$
F\left(V_{A}\right)=\int_{0}^{\mu+\sigma} \frac{1}{2 \sigma} V_{A}^{2} d V_{A}^{2}=\frac{(\mu+\sigma)^{2}}{4 \sigma}=E>0
$$

incremental investment and estimates a Q-model. 
We use the symbol $E$ to facilitate the discussion in later parts of this paper. It is optimal to invest in period 1 if $V_{A}^{l}>F\left(V_{A}\right)$. Otherwise the firm will postpone the investment decision until period 2. In line with the real options literature our model indicates that the net present value rule is incorrect (Dixit and Pindyck, 1994). In fact equation (1) shows that the net present value of the investment in period $1, V_{A}{ }^{1}$, should be strictly larger than zero to be willing to invest in period 1. Furthermore it can shown straightforwardly that the higher the uncertainty

as measured by ó, the higher the value of delaying the investment: $\partial E / \partial \sigma>0$. This result indicates that higher uncertainty tends to depress investment. Various studies provide empirical support for this claim (see for instance Guiso and Parigi, 1999; Ghosal and Loungani, 2000). Finally, delaying the investment becomes more likely as the expected value of $V_{A}^{2}$ increases: $\quad \partial E / \partial \mu>0$.

\section{Two investment projects}

Suppose now that in addition to project A the firm has an alternative investment option called project B. If the firm chooses to invest in project B in period 1 this yields $V_{B}{ }^{1}$. The net present value of project B in the second period is randomly distributed as well. To simplify our analysis we assume that $V_{B}^{2}$ is also uniformly distributed on the interval [ì -ó, ì +ó]. In addition we presume that $V_{A}^{2}$ and $V_{B}^{2}$ are independent. These assumptions affect the generality of our results. However, the main argument presented in the paper that the firm has an incentive to learn which project is the most profitable one holds in a more general setting as well.

The objective of the paper is to provide insights concerning the role of financial constraints in determining investment in light of the real options approach. The importance of financing constraints has been well documented. Firms may face difficulties in acquiring 
external financial resources like bank loans or equity because of an information asymmetry between the firm's management and the bank concerning the profitability of investment opportunities. Alternatively the principals (i.e. holders of claims on the firm) cannot perfectly monitor the activities of their agent (i.e. the management team of the firm). ${ }^{2}$ Due to such capital market imperfections, firms may experience that a shortage of cash constraints investment if the terms at which bank loans can be obtained are unfavorable.

Irreversibility is important in our model. Suppose that the firm would be able to recover the initial expenses of its investments. In that case the firm could invest its financial resources in project $\mathrm{A}$ in period 1 for instance. However, if project $\mathrm{B}$ turns out to be more profitable the firm could reverse its decision to implement project A and start project B instead. Irreversibility does not allow for this possibility. We will show that irreversibility implies that a firm has an incentive to wait investing in a particular project, because the future returns of another competing project may be very promising. Implicitly we also presume that the returns of a project implemented in period 1 are insufficient to provide the required funds to start another project in period 2 as well. The best way of thinking about this aspect of the model is that each project's cash flow is spread over many periods.

To simplify our analysis we assume that the firm is not able to acquire any additional external funds to finance in vestment. The financial resources of the firm may be used to start an investment project. If financial constraints are not binding the firm may choose to invest in both project A and B. In fact, the firm should apply the methodology depicted in section 1 to both projects separately, since the value of the firm is additive in the values of the two projects. This means that the firm will invest in project $\mathrm{A}$ in the first period if and only if $V_{A}{ }^{l}$ $F\left(V_{A}\right)$, and consider its investment in the second period otherwise. The firm will undertake project $\mathrm{B}$ in period 1 if and only if $V_{B}{ }^{l} \quad F\left(V_{B}\right)$ and decide on investment in the second period

\footnotetext{
${ }^{2}$ See Hubbard (1998) for an excellent review of this literature.
} 
otherwise. Obviously the value $F\left(V_{B}\right)$ can be derived using the methodology described in the previous section.

However, if the firm faces a financial constraint it has the possibility to undertake one project at most. The financial constraint implies that by investing in project $\mathrm{A}$ the firm gives up the option to invest in project B. The decision whether to invest in the first period depends on the expected value of the two investment projects A and B in the second period. Therefore we start solving the firm's decision in the second period:

$\begin{array}{ll}\text { invests in A if } & V_{A}^{2} \quad V_{B}^{2} \text { and } V_{A}^{2} \quad 0, \\ \text { invests in B if } & V_{B}{ }^{2}>V_{A}{ }^{2} \text { and } V_{B}^{2} \quad 0, \\ \text { does not invest if } & V_{A}{ }^{2}<0 \text { and } V_{B}{ }^{2}<0 .\end{array}$

In figure 1 we show in which instances the firm invests in either project $A$, project $B$ or abstains from investing in period 2. The horizontal axis denotes the possible realizations of $V_{A}{ }^{2}$. The vertical axis depicts the values $V_{B}^{2}$ can assume. In the areas I and II (where $V_{A}^{2} V_{B}^{2}$ and $V_{A}^{2} \quad$ 0) the firm selects project $\mathrm{A}$. The firm prefers project $\mathrm{B}$ in the areas denoted by III and IV (where $V_{B}^{2}>V_{A}^{2}$ and $V_{B}^{2} \quad 0$ ). The firm does not invest if $V_{A}^{2}<0$ and $V_{B}^{2}<0$ in which case areas $\mathrm{V}$ and VI are relevant. The presence of project $\mathrm{B}$ in addition to project $\mathrm{A}$ affects the expected net return from investing in period 2 for two reasons. First, project B allows the firm to obtain a higher return from investment in area III where the firm would have earned $V_{A}^{2}<V_{B}^{2}$ if project B did not exist. Secondly, the possibility of selecting B allows the firm to invest in more instances (area IV).

We assume that the firm cannot sell the investment option that it did not implement to another firm, because the option results from firm specific resources or capabilities that 
cannot be imitated or transferred to other companies (see Barney, 1991). Therefore in the first period the expected value of the two investment projects is given by (see the appendix):

$$
\begin{aligned}
F\left(V_{A}, V_{B}\right) \quad=\int_{0}^{\mu+\sigma} \int_{\mu-\sigma}^{V_{A}} \frac{V_{A}}{4 \sigma^{2}} d V_{B} d V_{A}+\int_{0}^{\mu+\sigma} \int_{\mu-\sigma}^{V_{B}} \frac{V_{B}}{4 \sigma^{2}} d V_{A} d V_{B}= \\
=\frac{\frac{1}{3}(\mu+\sigma)^{2}-\frac{1}{2}(\mu+\sigma)^{2}(\mu-\sigma)}{2 \sigma^{2}}
\end{aligned}
$$

Since we assume that ó>ì it can be shown after some straightforward calculations that

$$
F\left(V_{A}, V_{B}\right) \quad=E\left(1 \frac{2}{3}-\frac{1}{3} \frac{\mu}{\sigma}\right)>1 \frac{1}{3} E
$$

where $E$ is defined in equation (1). To recall, the quantity $E$ represents the critical value for each investment opportunity at which the firm is willing to undertake either project A or B in period 1 if the firm does not face a financial constraint. Equation (4) indicates that the presence of two investment opportunities in combination with a financial constraint raises the critical benchmark at which the firm finds it optimal to invest in the first period by more than 33 percent. This is due to the fact that by investing in either A or B the firm gives up the opportunity to invest in the other project later, which may be undesirable because it may yield a favorable outcome in the future.

The results above suggest that the timing of investment by financially constrained and unconstrained firms will differ. Suppose that a population of firms exists in which each firm considers the same investment projects A and B. Firms that do not face a shortage of cash are more likely to start project $\mathrm{A}$ or $\mathrm{B}$ in the first period than financially constrained firms, because the critical value $E$ at which these firms are willing to invest is lower than that of the constrained firms. 
It can be shown that if the expected value of the future returns of the two projects, i.e.

ì, increases that:

$$
\frac{\partial F\left(V_{A}, V_{B}\right)}{\partial \mu}=\frac{\mu+\sigma}{2 \sigma}\left(\frac{3}{2}-\frac{1}{2} \frac{\mu}{\sigma}\right)>\frac{\mu+\sigma}{2 \sigma}>0
$$

This result implies that the firm's incentive to delay the investment decision increases with a higher expected future return ì. The same holds if the parameter ó measuring the amount of uncertainty surrounding the projects increases:

$$
\frac{\partial F\left(V_{A}, V_{B}\right)}{\partial \sigma}=\frac{\partial E}{\partial \sigma}\left(1 \frac{2}{3}-\frac{1}{3} \frac{\mu}{\sigma}\right)+\frac{1}{3} E \frac{\mu}{\sigma^{2}}>\frac{\partial E}{\partial \sigma}\left(1 \frac{1}{3}\right)+\frac{1}{3} E \frac{\mu}{\sigma^{2}}>0
$$

Therefore, higher uncertainty tends to increase the incentive to postpone investing.

\section{3. $\quad \mathrm{N}$ investment projects}

The above findings readily extent to the case where the financially constrained firm has the opportunity to choose one project out of $N$ possibilities. Like in the previous section we assume that the future returns of project $i$ denoted by $V_{i}^{2}$ are identically and independently distributed on the interval [ì -ó, ì +ó]. In the second period the firm:

$$
\begin{array}{ll}
\text { invests in project } i \text { if } & V_{i}^{2} \quad V_{j}^{2} \text { and } V_{i}^{2} \quad 0, \text { for } i \neq j, i, j \in\{1, \ldots, N\} \\
\text { does not invest if } & V_{i}^{2}<0 \text { for all } i, i \in\{1, \ldots, N\} .
\end{array}
$$

Using partial integration we show in the appendix that in the first period the expected value of these $N$ projects equals

$$
F\left(V_{A}, \ldots, V_{N}\right)=\sum_{i=1}^{N} \int_{0}^{\mu+\sigma} \int_{\mu-\sigma}^{V_{A}} \ldots \int_{\mu-\sigma}^{V_{A}} \frac{V_{i}}{2^{N} \sigma^{N}} d V_{i} \prod_{i \neq j} d V_{j}=
$$




$$
=(\mu+\sigma)-\frac{2 \sigma}{N+1}+\frac{(\sigma-\mu)^{N+1}}{(N+1)(2 \sigma)^{N}}
$$

After some straightforward but tedious calculations performed in the appendix we find for $N=2$ that the expression in equation (8) is equivalent to the one presented in equation (3).

In the appendix it is shown that if the number of projects increases with one the change in the expected value of the projects equals:

(9) $F\left(V_{A}, \ldots, V_{N+1}\right)-F\left(V_{A}, \ldots, V_{N}\right)=\frac{1}{(N+1)(N+2)}\left(2 \sigma-\left(\frac{\sigma-\mu}{2 \sigma}\right)^{N+1}((N+3) \sigma+(N+1) \mu)\right)$

Our assumptions made previously imply $0<1-\frac{\mu}{\sigma}<1$. Furthermore, by using mathematical induction it is verified in the appendix that for all $N 1$ it holds that $0<\frac{N+3}{2^{N+1}} \leq 1$ and $0<\frac{N+1}{2^{N+1}} \leq 1$. This implies that the change in the expected value of the projects is positive when the number of projects increases.

$$
F\left(V_{A}, \ldots, V_{N+1}\right)-F\left(V_{A}, \ldots, V_{N}\right)>\frac{1}{(N+1)(N+2)}(2 \sigma-(\sigma+\mu))>0
$$

Therefore, the critical value at which the firm is willing to invest increases with the number of projects. Loosely interpreted, financing constraints become tighter as $N$ increases since the firm can only select one project. Therefore, the above result in equation (10) indicates that tighter financing constraints increase the value of waiting.

If the number of projects increases to infinity the expected value of the projects becomes:

$$
\lim _{N \rightarrow \infty} F\left(V_{A}, \ldots, V_{N}\right)=\mu+\sigma
$$


The result follows from the fact that all random variables $V_{i}^{2}$ are identically and independently distributed on the interval [ì-ó, ì +ó]. If the number of projects increases to infinity then with probability one in the second period the value of one of these projects will be ì +ó, the maximum realization possible.

We also find that the value of the investment projects increases with the expected future benefits of the projects:

$$
\frac{\partial F\left(V_{A}, \ldots, V_{N}\right)}{\partial \mu}=1-\frac{1}{(N+1)^{2}} \frac{1}{2^{N}}\left(1-\frac{\mu}{\sigma}\right)^{N}
$$

Since the three terms after the minus sign in the above equation are all larger than zero but smaller than 1, the sign of the derivative is positive, implying that the firm is willing to wait longer if the future prospects of the projects improve. Finally, as we show in the appendix higher uncertainty increases the value of the investment projects in the future as well:

$$
\frac{\partial F\left(V_{A}, \ldots, V_{B}\right)}{\partial \sigma}=1-\frac{2}{N+1}+\frac{(\sigma-\mu)^{N}}{(N+1) 2^{N}}\left(\frac{\sigma+N \mu}{\sigma^{N+1}}\right)>0
$$

Hence, as uncertainty increases it becomes more likely that the firm will wait with the investment to see which of the $N$ projects is the most fruitful one.

\section{Conclusion}

We have studied a model in which a firm has a number of potential investment projects. Due to financial constraints it can select only one of these projects. The firm decides to implement one of these projects as the immediate return of this particular project exceeds a certain critical value. This critical value increases if the number of potential projects becomes larger. The reason is that there exists an option value of waiting, because the decision to 
choose a particular project cannot be reversed. Therefore, waiting allows the firm to learn which project is the best one if future profitability is uncertain. The model employed in this paper is restrictive in a number $\boldsymbol{\Phi}$ ways. First, we assume that the firm can only delay its investment decision one period. Second, the risk characteristics of all projects are identical. We conjecture that those features of the model do not affect the main insights we present in the paper. 


\section{$\underline{\text { Bibliographic References }}$}

Barney, J.; 1991, Firm Resources and Sustained Competitive Advantage, Journal of Management, vol. 17, pp. 99-120

Dixit, A.K., and R.S. Pindyck; 1994, Investment under Uncertainty, Princeton University Press

Ghosal, V. and P. Loungani; 2000, The differential impact of uncertainty on investment in small and large businesses, The Review of Economics and Statistics, vol. 82, pp. 338-349.

Press, pp. 15-42.

Guiso, L. and G. Parigi; 1999, "Investment and Demand Uncertainty", Quarterly Journal of Economics, vol. 114, pp. 185-227

Hubbard, R.G.; 1998, Capital Market Imperfections and Investment, Journal of Economic Literature, Vol. 36, pp. 193-225

Scaramozzino, P.; 1997, "Investment Irreversibility and Finance Constraints", Oxford Bulletin of Economics and Finance Constraints, vol.35, pp. 89-108. 
Figure 1

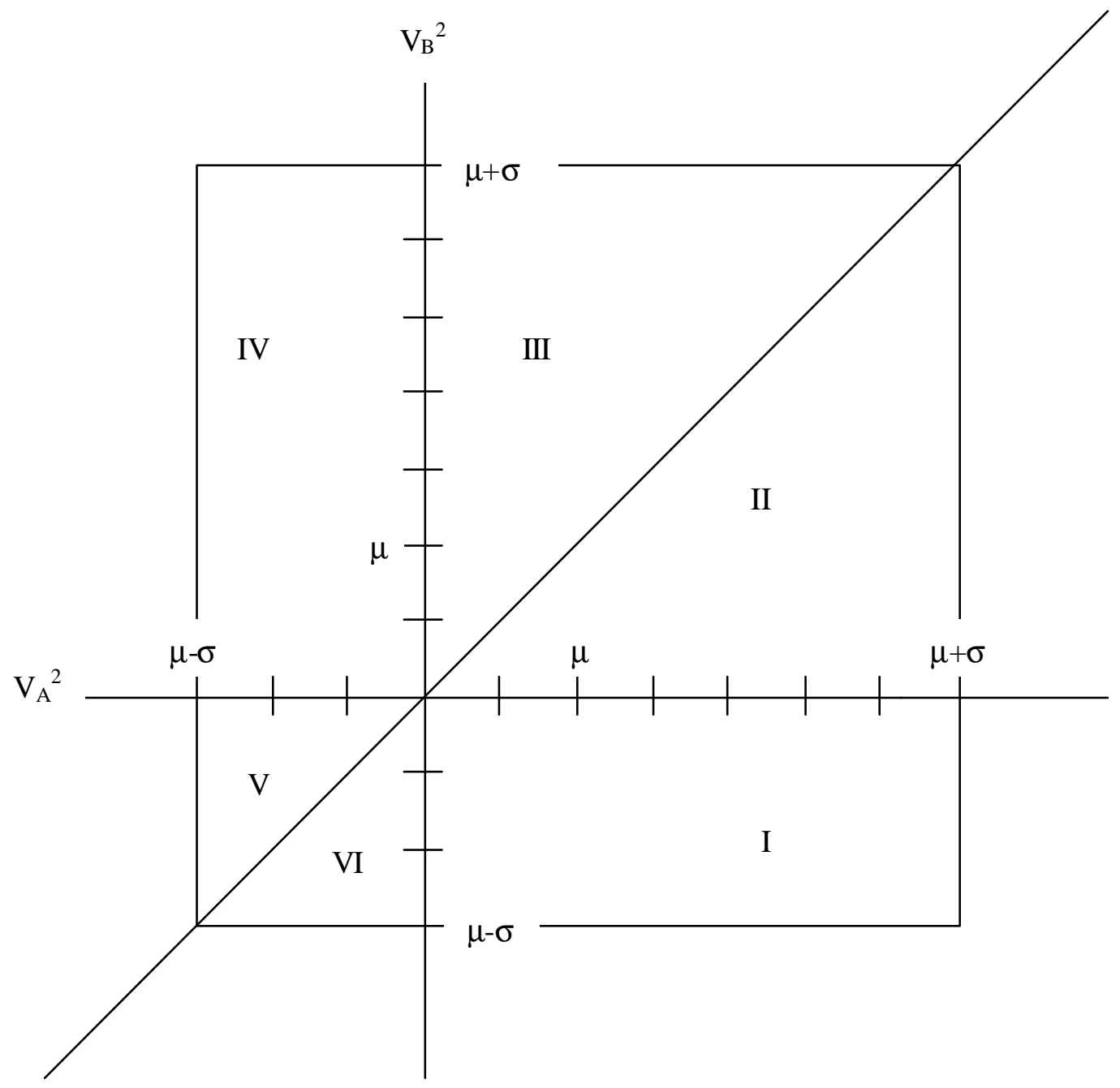




\section{Appendix}

\section{Derivation equation (3)}

Since the two terms in $\int_{0}^{\mu+\sigma} \int_{\mu-\sigma}^{V_{A}} \frac{V_{A}}{4 \sigma^{2}} d V_{B} d V_{A}+\int_{0}^{\mu+\sigma} \int_{\mu-\sigma}^{V_{B}} \frac{V_{B}}{4 \sigma^{2}} d V_{A} d V_{B}$ are equal, we find that $F\left(V_{A}, V_{B}\right)=2 \int_{0}^{\mu+\sigma} \int_{\mu-\sigma}^{V_{A}} \frac{V_{A}}{4 \sigma^{2}} d V_{B} d V_{A}=\frac{1}{2 \sigma^{2}} \int_{0}^{\mu+\sigma} V_{A}\left(V_{A}-\mu+\sigma\right) d V_{A}$

It is straightforward to show that the above integral is equal to the expression in (3).

\section{Derivation equation (8)}

Since the $N$ terms of $\sum_{i=1}^{N} \int_{0}^{\mu+\sigma} \int_{\mu-\sigma}^{V_{i}} \ldots \int_{\mu-\sigma}^{V_{i}} \frac{V_{i}}{2^{N} \sigma^{N}}\left(\prod_{i \neq j} d V_{j}\right) d V_{i}$ are equal,

$F\left(V_{1}, \ldots, V_{N}\right)=\frac{N}{(2 \sigma)^{N}} \int_{0}^{\mu+\sigma} V_{i}\left(V_{i}-\mu+\sigma\right) \quad d V_{i}=\frac{N}{(2 \sigma)^{N}}\left(\frac{(\mu+\sigma)(2 \sigma)^{N}}{N}-\int_{0}^{\mu+\sigma} \frac{\left(V_{i}-\mu+\sigma\right)^{N}}{N} d V_{i}\right)=$

$(\mu+\sigma)-\frac{N}{(2 \sigma)^{N}}\left(\frac{(2 \sigma)^{N+1}}{(N+1) N}-\frac{(\sigma-\mu)^{N+1}}{(N+1) N}\right)$. This is equal to the expression in equation (8).

Derivation that for $N=2$ equation (8) equals equation (3).

Starting with equation (8),

$$
\begin{aligned}
& F\left(V_{1}, V_{2}\right)=\frac{1}{2 \sigma^{2}}\left(2 \sigma^{2} \mu+2 \sigma^{3}-\frac{4}{3} \sigma^{3}+\frac{1}{6}(\mu+\sigma-2 \mu)^{3}\right)= \\
& \frac{1}{2 \sigma^{2}}\left(2 \sigma^{2} \mu+\frac{2}{3} \sigma^{3}+\frac{1}{6}\left((\mu+\sigma)^{3}-6 \mu(\mu+\sigma)^{2}+12 \mu^{2}(\mu+\sigma)-8 \mu^{3}\right)\right)= \\
& \frac{1}{2 \sigma^{2}}\left(\frac{1}{3}(\mu+\sigma)^{3}+2 \sigma^{2} \mu+\frac{2}{3} \sigma^{3}+\frac{1}{6}\left(-(\mu+\sigma)^{3}-6 \mu(\mu+\sigma)^{2}+12 \mu^{2}(\mu+\sigma)-8 \mu^{3}\right)\right)= \\
& \frac{1}{2 \sigma^{2}}\left(\frac{1}{3}(\mu+\sigma)^{3}-\frac{1}{2}\left(\mu^{3}+\mu^{2} \sigma-\sigma^{2} \mu-\sigma^{3}\right)\right) . \text { Equation (3) follows immediately. }
\end{aligned}
$$


Derivation of equation (9)

$F\left(V_{1}, \ldots, V_{N+1}\right)-F\left(V_{1}, \ldots, V_{N}\right)=\left(\frac{1}{N+1}-\frac{1}{N+2}\right) 2 \sigma+\left(\frac{\sigma-\mu}{2 \sigma}\right)^{N+1}\left(\frac{\sigma-\mu}{N+2}-\frac{2 \sigma}{N+1}\right)=$

$\frac{2 \sigma}{(N+1)(N+2)}+\left(\frac{\sigma-\mu}{2 \sigma}\right)^{N+1}\left(\frac{(N+1)(\sigma-\mu)-2 \sigma(N+2)}{(N+1)(N+2)}\right)$. This can be used to derive equation (9).

\section{Derivation of equation (10)}

We need to show that for all $N>1,0<A_{N}=\frac{N+3}{2^{N+1}} \leq 1$ and $0<B_{N}=\frac{N+1}{2^{N+1}} \leq 1$. It is sufficient to show that $0<A_{N} \leq 1$ since $A_{N}>B_{N} . A_{N}>0$ is obvious. For $N=1, A_{N}=1$. Suppose that our claim holds for $N . A_{N+1}=\frac{N+3+1}{2^{N+2}}=\frac{A_{N}}{2}+\frac{1}{2^{N+2}} \leq \frac{1}{2}+\frac{1}{2^{N+2}} \leq 1$. Our assumptions made previously imply $0<1-\frac{\mu}{\sigma}<1$. Equation (10) follows straightforwardly. $Q E D$.

Derivation of equation (13).

$\frac{\partial F\left(V_{1}, \ldots, V_{N}\right)}{\partial \sigma}=1-\frac{2}{N+1}+\frac{1}{(N+1) 2^{N}}\left(\frac{(N+1)(\sigma-\mu)^{N} \sigma^{N}-(\sigma-\mu)^{N+1} N \sigma^{N-1}}{\sigma^{2 N}}\right)=$
$=1-\frac{2}{N+1}+\frac{(\sigma-\mu)^{N}}{(N+1) 2^{N}}\left(\frac{(N+1) \sigma-(\sigma-\mu) N}{\sigma^{N+1}}\right)$. Equation (13) can be obtained by collecting terms. $\frac{\partial F\left(V_{1}, \ldots, V_{N}\right)}{\partial \sigma}$ is positive, since $1-\frac{2}{N+1}$ is positive for $N>1$ and $\left(\frac{(N+1) \sigma-(\sigma-\mu) N}{\sigma^{N+1}}\right)>0$. 